\title{
Facilitating Implementation and Promoting Compliance With the Paris Agreement Under Article 15: Conceptual Challenges and Pragmatic Choices
}

\section{Gu Zihua}

Department of Treaty and Law, Ministry of Foreign Affairs of China gu_zihua@mfa.gov.cn

\section{Christina Voigt}

Department of Public and International Law, University of Oslo christina.voigt@jus.uio.no

\section{Jacob Werksman}

Directorate General for Climate Action, European Commission jacob.werksman@ec.europa.eu

\section{Abstract}

This article provides a comprehensive overview of the modalities and procedures for the effective operation of the committee tasked to facilitate implementation of and promote compliance with the provisions of the Paris Agreement (the Article 15 Committee). This is done in the context of the negotiation history and the object and purpose of the Agreement. The article explains how the Committee is expected to function, which situations trigger its proceedings and which outcomes can be expected. Importantly, the article explores the linkages to other processes and mechanisms under the Paris Agreement, especially to the Enhanced Transparency Framework, and explains how the Committee will add value to the Paris Agreement's architecture. ${ }^{1}$

\section{Keywords}

Paris Agreement, implementation, compliance, facilitative, modes of initiation, measures

\section{Introduction and Overview}

\footnotetext{
${ }^{1}$ Gu Zihua was negotiator for China on the 'Modalities and procedures for the effective operationalization of committee referred to in Article 15, paragraph 2, of the Paris Agreement'. The views expressed in this article are personal to him and do not necessarily represent the position of the Government of China. Christina Voigt has been lead legal negotiator for the Government of Norway in the UN climate change negotiations since 2013, and was co-facilitator for the negotiations on the 'Modalities and procedures for the effective operationalization of committee referred to in art. 15, para 2, of the Paris Agreement' in 2018. The views expressed in this article are personal to her and do not necessarily represent the position of the Government of Norway. Jacob Werksman is Principal Adviser for International Aspects of European Climate Policy and a lead negotiator for the European Union since 2014. The views expressed in this article are personal to him and do not necessarily represent the position of the Commission or the Union.
} 
The 2015 Paris Agreement will shape state behaviour through a variety of obligations and procedural arrangements. Each party must prepare, communicate, and maintain a Nationally Determined Contribution (NDC). An Enhanced Transparency Framework (ETF) will track each party's progress towards the implementation and achievement of its NDC. A Global Stocktake will, every five years, assess parties' collective progress towards the Agreement's goals and provide the basis for increasing the ambition of individual NDCs and collective effort. And a mechanism, consisting of a committee, will 'facilitate implementation of and promote compliance with the provisions' of the Agreement (the Article 15 Committee).

The Article 15 Committee is expected to enhance the effective functioning of the Paris Agreement both by encouraging parties to implement the Agreement and by holding them accountable for aspects of their performance. This should build confidence and trust among the parties to the Agreement. ${ }^{2}$ Several modern multilateral environmental agreements, including the 2013 Minamata Convention on Mercury and the 1997 Kyoto Protocol, have standing committees with a mandate to oversee implementation and compliance by parties. ${ }^{3}$ Similar to those other committees, the Article 15 Committee has been tailored to fit the unique characteristics of the regime it serves. ${ }^{4}$

While a number of the Committee's essential characteristics are set out in the treaty's Article 15, as well as in the decision adopting the Agreement, ${ }^{5}$ more detailed modalities and procedures were necessary to ensure its effective operation. These have now been agreed to as part of the Rulebook that will guide the implementation of the Agreement. ${ }^{6}$ The Rulebook was adopted at the conclusion of the first meeting of the Agreement's governing body (CMA 1) in December 2018 in Katowice, Poland. ${ }^{7}$

By adopting these modalities and procedures, the CMA has resolved many of the differences in view among parties regarding the Committee's nature, purpose, and

${ }^{2}$ Christina Voigt, 'The Compliance and Implementation Mechanism of the Paris Agreement', 25(2) Review of European, Comparative \& International Environmental Law 1 (2016).

${ }^{3}$ Jutta Brunnée, Meinhard Doelle, \& Lavanya Rajamani (eds.), Promoting Compliance in an Evolving Climate Regime (Cambridge, UK: Cambridge University Press 2012) (hereinafter Brunnée et al. 2012).

${ }^{4}$ Yamide Dagnet and Eliza Northrop, 'Facilitating Implementation of and Promoting Compliance (Article 15)', in Daniel Klein, María Piá Carazo, Meinhard Doelle, Jane Bulmer, and Andrew Higham (eds.), The Paris Agreement on Climate Change - Analysis and Commentary (Oxford, UK: Oxford University Press 2017); see also Voigt, supra note 2.

${ }^{5}$ UNFCCC, Decision 1/CP.21, Report of the Conference of the Parties on its twenty-first session, held in Paris from 30 November to 13 December 2015, FCCC/CP/2015/10/Add.1 (2016), available at https://unfccc.int/resource/docs/2015/cop21/eng/10a01.pdf, (hereinafter Decision 1/CP.21 and PA, referring to the Paris Agreement contained in the Annex), paras 102 and 103.

${ }^{6}$ Paris Agreement, Draft decision -/CMA.1, Modalities and Procedures for the effective operation of the committee to facilitate implementation and promote compliance referred to in Article 15, paragraph 2, of the Paris Agreement, FCCC/CP/2018/L.5 (2018), available at https://unfccc.int/sites/default/files/resource/105 2.pdf (hereinafter A15 MP).

${ }^{7}$ Paris Agreement, Draft decision -/CMA.1, Matters relating to the implementation of the Paris Agreement, advance unedited version (2018), available at

https://unfccc.int/sites/default/files/resource/cp24_auv_3cma1_final.pdf. 
function. In general, a balance has been struck that respects the 'nationally determined' nature of parties' NDCs; the tailored legal character of the Agreement's provisions; the scope and balance of the Agreement's legal obligations, including the different reflections of common but differentiated responsibilities and respective capabilities, in the light of different national circumstances; the facilitative, non-punitive, and nonadversarial nature of the Committee's mandate; and the distinct and complementary roles of the Committee and the Agreement's ETF.

To reach this shared understanding, the negotiations addressed, in particular:

1. how the Article 15 Committee could play an effective role without duplicating that of the Agreement's ETF or other processes under the Agreement;

2. whether the Committee's mandate to facilitate implementation and promote compliance implied the same or two distinct functions;

3. whether the Committee's scope was applicable to all of the Agreement's provisions or limited to, for example, mandatory obligations applicable to parties individually;

4. whether the Committee's scope would include a review of a party's performance against the Rulebook's provisions;

5. whether the Committee could engage with a party on its own initiative or only at the request or with the consent of the party concerned;

6. how to ensure that the Committee's measures and outputs would provide incentives that would facilitate implementation and promote compliance while not interfering with the work of the Agreement's financial and technical support bodies and while remaining non-punitive in nature;

7. how the Committee could address implementation and compliance issues of a 'systemic nature';

8. the extent to which the modalities and procedures would leave discretion to the Committee to carry out its functions and how much would need to be incorporated into the rules of procedure elaborated by the Committee (due to be adopted by CMA 3 in 2020); and

9. how to make the best use of the standing nature of the Committee and the expertise of its members.

The parties achieved agreement on these issues by grappling with a number of conceptual issues and by finding pragmatic solutions. They also left the Committee with considerable discretion to interpret its modalities and procedures.

This article begins with an overview of the conceptual issues, both legal and political, that framed the debates on the Committee's design and functioning, including how the Committee's mandate of 'facilitating implementation and promoting compliance' relates to the legal character of the Agreement's provisions. We then move to a description of how the Committee's institutional arrangements - a standing body of 
experts- bestow on it the potential to add value to other arrangements under the Agreement that will play a role in encouraging parties to implement the Agreement and strengthen their actions over time. Through a review of the pragmatic solutions on measures and outputs that the Committee has been authorized to take, we argue that the Committee should be able to help parties that are experiencing challenges in implementing the provisions of the Agreement and hold accountable those that fail to comply with clearly identified provisions of the Agreement and Rulebook. We then examine the three modes of initiation of the Committee's procedures under the Rulebook, which mandate the Committee to:

1. In cases of self-referral by a party, address at its discretion issues with regard to any of the Agreement's provisions, according to paragraph 20 (Mode 1).

2. Initiate automatically procedures related to specified legally binding provisions of the Agreement that are not reported on or taken up or reviewed by the ETF or other processes under the Agreement, according to paragraph 22(a) (Mode 2).

3. At its discretion and subject to the consent of the party concerned, address cases of significant and persistent inconsistencies in the information provided by a party with certain provisions of the modalities, procedures, and guidelines (MPGs) under the ETF, according to paragraph 22(b) (Mode 3).

We review each of these modes of initiation and identify the relevant procedural arrangements and the measures the Committee may take with regard to the party concerned, and we consider whether any gaps are left in the scope of the Committee's work. With regard to the 'cases' that the Committee would address in each of the modes, we assess how the available measures and outputs might create incentives for a party to implement and comply with the relevant provisions.

We also demonstrate how the Committee could complement and add value to the Agreement by addressing a party's performance of key legally binding provisions of the Agreement that are not reviewed by the ETF, assisting the party to engage with appropriate support arrangements under the Paris Agreement, and 'backstopping' the oversight of a party's performance in relation to identified significant and persistent inconsistencies identified but left unresolved by the ETF. Furthermore, we describe how the Committee could identify and examine issues of a systemic nature faced by a number of parties, although without addressing the performance of any individual party. We also touch briefly on any role the Committee might play with regard to oversight of the use of 'cooperative approaches' (or market mechanisms) under Article 6 of the Agreement.

Throughout the article we discuss how the Committee has been left with considerable discretion in how it will perform its work-including through the development of more 
detailed rules of procedure. However, the Rulebook has put in place important institutional and procedural safeguards to ensure that the Committee preserves the essentially facilitative nature of the process, addresses differences in parties' respective national capabilities and circumstances, and respects the sovereignty of the parties concerned, while aiming to enhance the effectiveness of the Agreement.

\section{Conceptual Issues that Framed the Debate on the Committee's Modalities and Procedures}

The international legal character and normative strength of the Paris Agreement were the subject of intense political and academic debates during its negotiation. ${ }^{8}$ According to the mandate that launched the negotiations, the agreed outcome was to have 'legal force'. ${ }^{9}$ During the negotiations, it was clear that a number of parties wanted it to result in a legally binding treaty with correspondingly binding obligations. Some wanted the Agreement to include, in particular, binding emission-reduction targets and timetables. In any case, many parties supported a role for what became the Article 15 Committee in reviewing the performance of parties in relation to legally binding obligations and associated the word 'compliance' with this function. Some parties preferred an Agreement that was less or non-binding, and sought to limit the mandate of a Committee to facilitating the 'implementation' of the Agreement. Yet another group of parties supported a binding treaty with binding obligations, but feared that describing the Committee as having a 'compliance' function might lead others to push for less stringent obligations.

In the end, the Paris Agreement is treaty within the meaning of the Vienna Convention on the Law of Treaties, ${ }^{10}$ but creates binding obligations for parties mainly with regard to their procedural conduct rather than substantive performance of result. The emission-

\footnotetext{
${ }^{8}$ See e.g, Daniel Bodansky, 'The Legal Character of the Paris Agreement', 25(2) Review of European, Comparative \& International Environmental Law 142 (2016), who notes that the debate over the legal character of the Paris Agreement has continued - particularly among US academics - even after the Agreement was adopted and entered into force. He summarizes the source of the debate as confusion about the different characteristics of legal form. He concludes that the Paris Agreement is a treaty within the definition of the Vienna Convention on the Law of Treaties, but not every provision of the agreement creates a legal obligation. It contains a mix of mandatory and non-mandatory provisions. The debate clearly has additional political and legal dimensions in the US, where even supporters of the Agreement consistently refer to it as the 'Paris Accord' in an apparent effort to support the Obama Administration's decision to join the Agreement by acceptance, through executive authority rather than through the treaty approval powers of the US Senate.

9 UNFCCC, Decision 1.CP/17, Report of the Conference of the Parties on its seventeenth session, held in Durban from 28 November to 11 December 2011, FCCC/CP/2011/9/Add.1 (2012), available at https://unfccc.int/resource/docs/2011/cop17/eng/09a01.pdf, para 2.

${ }_{10}$ A treaty under international law is an 'international agreement concluded between states in written format and governed by international law, whether embodies in a single instrument or in two or more related instruments and whatever its particular designation.' 1969 Vienna Convention on the Law of Treaties, Vienna, 23 May 1969, in force 27 January 1980, 25 ILM 679 (1969) (hereinafter VCLT), art. 2.
} 
reduction targets and actions that represent each party's NDC are set in a nationally determined manner, and are non-binding as to their result. ${ }^{11}$

Article 15 similarly reflects a compromise. Overall, the Article 15 'mechanism' is described as 'facilitative' and 'non-punitive'. The Committee's mandate is 'facilitating implementation of and promoting compliance with the provisions' of the Agreement. Article 15 does not indicate how this mandate will apply to which of the Agreement's provisions - whether binding or non-binding.

In the course of the Rulebook negotiations, some delegations maintained that 'facilitating implementation' and 'promoting compliance' were intended to be distinct functions, with the latter being applicable only to the Agreement's binding provisions. Accordingly, the two functions should correspond to distinct procedures of the Committee and result in different outcomes. The same parties argued that parties' compliance with legally binding obligations is a fundamental requirement for the effective functioning of the Agreement. ${ }^{12}$ For this reason, they considered that while the facilitation of implementation could apply to any of the Agreement's provisions, additional initiation modes and measures would be needed to ensure that parties comply with their legally binding commitments. ${ }^{13}$

Other parties argued that the terms implementation and compliance are not inherently distinct or distinctly associated with the performance of binding or non-binding provisions. Those parties argued that, instead, the terms represent a compromise in the text intended to give the Committee discretion to address a range of important provisions with a range of outcomes. Nevertheless, all parties recognized that, whatever the legal character of the provision being addressed, the Committee was to remain facilitative and non-punitive and could not change that legal character.

These conceptual debates, legal and political, which influenced the outcome of the Article 15 modalities and procedures, have not been entirely resolved. As the core

\footnotetext{
${ }^{11}$ Lavanya Rajamani, 'The 2015 Paris Agreement: Interplay Between Hard, Soft and Non-Obligations', 28(2) Journal of Environmental Law 337 (2016).

12 See e.g. Submission by Norway on APA agenda item 7 Modalities and procedures for the effective operation of the committee under the mechanism to facilitate implementation of and promote compliance with the provisions of the Paris Agreement (Article 15, paragraph 2) (3 November 2016) and Submission by Norway on APA agenda item 7 (4 April 2017), both available at https://unfccc.int/process/bodies/subsidiary-bodies/ad-hoc-working-group-on-the-paris-agreementapa/information-on-apa-agenda-item-7/submissions-received-on-apa-item-7.

${ }^{13}$ See e.g. AILAC submission on Article 15 mechanism (13 March 2017), available at https://unfccc.int/process/bodies/subsidiary-bodies/ad-hoc-working-group-on-the-paris-agreementapa/information-on-apa-agenda-item-7/submissions-received-on-apa-item-7 (hereinafter AILAC submission).
} 
analysis of this article describes, parties settled on a set of pragmatic compromises, as well as a few unresolved inconsistencies. ${ }^{14}$

As we will explain in more detail later, the pragmatic solutions include the following:

The three modes of initiation apply differently to identified provisions of the Agreement and the Rulebook. The cases that the Committee must take automatically (Mode 2)

relate to specific treaty-based provisions that are uncontroversially binding in character, whereas the Committee is afforded discretion on whether to take up cases related to certain other provisions of the Agreement and the Rulebook, and then only upon the initiative of or with the consent of the party (Modes 1 and 3). The Committee also has discretion to take up any issue raised by a party related to its own implementation of, or compliance with, any provision, whether binding or non-binding (Mode 1).

As a result of its consideration of a case, and irrespective of initiation mode, the Committee shall take appropriate measures. When identifying such measures, the Committee is to be informed, among other things, by the legal character of the relevant provisions. The issuance of 'findings of fact' (which might be considered the most stringent measure in the list) refers only to matters referred to in paragraph 22(a) of the Committee's modalities and procedures. ${ }^{15}$ This may be understood as a deliberate strengthening of the Committee's ability to promote parties' compliance with the legally binding provisions set out in paragraph 22(a) in the Annex to the Rulebook`s decision on the modalities and procedures for the Article 15 Committee. ${ }^{16}$

These distinctions in treatment appear to create a hierarchy between the covered provisions that reflects differences in their legal character. Once the Committee has taken up a case, its discretion will be guided with regard to legal character by the modalities and procedures which provide that 'nothing in the work of the Committee may change the legal character of the provisions of the Paris Agreement. ${ }^{, 17}$

\section{Institutional Arrangements Adding Value to the Agreement}

\footnotetext{
${ }^{14}$ For example, the Rulebook only makes an explicit distinction between 'implementation' and/or 'compliance' in the description of 'Mode 1' initiation of a party with regard to itself. While Modes 2 and 3 do not mention either 'compliance' or 'implementation', an implicit distinction between those two notions can be seen in the respective 'automatic' and 'discretionary' modes of initiation. Similarly, the 'measures or outputs' the Committee may take under any mode of initiation do not explicitly distinguish between 'implementation' and 'compliance', but the Committee shall be informed by the legal nature of the provisions when taking appropriate measures and is limited to agreeing 'findings of fact' with regard to the treaty-based obligations listed in para 22(a).

${ }^{15}$ A15 MP, supra note 6, Annex, para 30(e). (If not specified otherwise, references in the text to paragraphs of the 'Article 15 Decision' refer to those contained in the decision's Annex.)

${ }^{16}$ Ibid., Annex, para 22(a).
} 
The Committee is part of the mechanism established under Article 15.1 of the Agreement. It is a standing, expert body with a mandate to address situations related to the performance of individual parties. These general parameters together with the modalities and procedures in the Rulebook have the potential to add significant value to the processes under the Agreement.

First, the Committee's membership The Committee is to be geographically and politically representative. It will consist of twelve members (plus twelve alternates), as shown in Table $1 .^{18}$ Its design reflects an effort by some parties to avoid reference to the categories of developed and developing countries or to the UNFCCC's Annexes. ${ }^{19}$

Table 1. Size and composition of the Article 15 Committee.

\section{Grouping}

African Group

Asia Pacific Group

Eastern European Group

Group of Latin American and Caribbean Countries

Western European and Other Group

Small Island Developing States

Least Developed Countries

Subtotal

Total

$\begin{array}{cc}\text { 'Developed' } & \text { 'Developing' } \\ & 2 \\ 2 & 2 \\ 2 & 2 \\ & \\ & \\ 4 & 1 \\ & \mathbf{8}\end{array}$

(+12 alternates)

The identified groupings represent a political balance relevant to a context where a number of provisions covered by the Committee apply to developed-country parties only ${ }^{20}$ and where the reporting guidelines reviewed by the Committee contain flexibilities for those developing countries that need it in light of their capacity. ${ }^{21}$

\footnotetext{
${ }^{18}$ Decision 1/CP.21, supra note 5, para 102 and ibid., para 5. The composition of the committee was already decided at COP2 1 in Paris and benefitted from the unique political momentum at that time. Parties wished to avoid the situation that arose under the UNFCCC, where the Convention calls for the establishment of a 'multilateral consultative process . . . for the resolution of questions regarding the implementation of the Convention' (UNFCCC, art. 13). The process never became operational in part because parties were never able to agree the size and composition of the Committee designed to run the process. See Lavanya Rajamani, 'Developing Countries and Compliance in the Climate Regime' in Jutta Brunnée et al. 2012, supra note 3, 387-390.

${ }^{19}$ In effect, the use of the UN regional groupings results in fewer representatives of countries categorized as 'developed' under the UNFCCC than are included in UNFCCC institutions of a similar size. For example, the Executive Committee of the Warsaw International Mechanism on Loss and Damage, established in 2013, has 10 members from parties included in Annex I, and 12 non-Annex members, UNFCCC, Decision 2/CP.20 Report of the Conference of the Parties on its twentieth session, held in Lima from 1 to 14 December 2014, FCCC/CP/2014/10/Add.2 (2015), available at https://unfccc.int/documents/8612.

${ }^{20}$ See e.g. the commitment to provide information on support to developing countries, PA, art. 13.9.

${ }^{21}$ See discussion on Mode 3 initiation, below.
} 
Second, it is a standing body. Its membership remains in place between elections and between cases. It is not selected ad hoc. This means that the committee stands ready to address the issues which come before it, without any delay or cumbersome selection processes. ${ }^{22}$ Its members and alternates will be elected for a term of three years, and can serve a second term. ${ }^{23}$ The Committee will meet at least twice a year, but it can also carry out its work continuously between sessions. ${ }^{24}$ Earlier drafts of the decision text foresaw that work could be carried out by electronic means to support continuity. This option is now expected to be revisited in the context of agreeing to the Committee's rules of procedure.

Third, the Committee's design offers procedural continuity and predictability. With members serving up to six years in staggered terms, the design facilitates the consistent development and predictable application of its rules. A member who serves for six years will undoubtedly gain significant expertise with respect to both the procedures and the performance of parties. The use of alternates increases the likelihood that the necessary quorum (ten members) for decision-making will be attained. ${ }^{25}$ A member who is unable to complete a term or perform his or her functions is to be replaced by another expert from the same party. ${ }^{26}$ The provision for two co-chairs allows for equitable geographical representation; it also means that if one is unavailable, the Committee should still be able to carry out its functions. ${ }^{27}$

Fourth, the Committee should be able to develop an institutional memory, usually absent in ad hoc arrangements. The features just described, in combination with the institutional structure of the Committee and the support of the UNFCCC's Secretariat, should place the Committee in a position where, over time, lessons and experiences can build up to a guarantee of procedural effectiveness. New members should be able to rely on a base of information, experience, and best practice to save time in familiarizing

\footnotetext{
${ }^{22}$ In comparison, the technical expert review teams (TER Teams) are established on an ad hoc basis, with significant administrative involvement by the secretariat. The teams will have to be composed by the secretariat from the UNFCCC roster of experts, every time after the relevant information has been submitted (as each transparency report will be reviewed by a single expert team). The experts shall be nominated to that roster by parties or IOs. The secretariat will compose the teams taking into account skills and competences, coverage, language skills, balance between developed and developing countries, geographical and gender balance, and assign lead reviewers - one from a developed and one from a developing country. See Draft decision -/CMA.1, Modalities, procedures and guidelines for the transparency framework for action and support referred to in Article 13 of the Paris Agreement, FCCC/CP/2018/L.23 (2018), available at https://unfccc.int/sites/default/files/resource/123 0.pdf (hereinafter A13 MPG), paras 175-186. (Unless otherwise indicated, paragraph references in the text are to the Annex of this decision.)

${ }^{23}$ A15 MP, supra note 6, Annex, para 7.

${ }^{24}$ Ibid., Annex, para 12.

${ }^{25}$ Ibid., Annex, paras 15 and 16

${ }^{26}$ Ibid., Annex, para 9.

${ }^{27}$ Ibid., Annex, para 11.
} 
themselves with ongoing considerations, fasten learning processes, and ensure uninterrupted procedures.

Fifth, the Committee's composition will include a broad range of relevant expertise (scientific, technical, socioeconomic, legal). Members will serve in their individual and expert capacity based on 'recognised competence in relevant fields', while respecting gender balance. ${ }^{28}$ The considerable size of the Committee (compared, e.g., with the ad hoc Technical Expert Review Teams under the ETF) potentially draws on a wide range of expertise to offer a party. It should thus be well-positioned to address the wide spectrum of implementation or compliance issues that could come before it.

Sixth, the Committee has been equipped with effective decision-making procedures which have the potential to overcome deadlock. ${ }^{29}$ While it should reach its decisions by consensus, if this proves impossible after all efforts have been exhausted, voting rules apply. A decision then requires the vote of at least three-quarters of the members present and voting. With a quorum of ten, this means that at least eight members must vote in favour (nine if all twelve members are present). Any decision taken by vote when all members (or their alternates) are present would require a mixed majority of developed- and developing-country members, guarding against the influence of any vested interests.

Seventh, safeguards have been put in place to protect the legitimacy of the Committee's proceedings. The modalities and procedures ensure the confidentiality of information provided in confidence and protect against conflicts of interest in decision-making. ${ }^{30}$ The Rulebook's modalities and procedures do not explicitly say whether Committee meetings will be open to the public. However, they provide that only members and alternate members and Secretariat staff may be present during the elaboration and adoption of a decision. ${ }^{31}$ This suggests that at other times the Committee's meetings will be open. It is expected that this issue will be further considered during the development of the Committee' rules of procedure. ${ }^{32}$ In any event, confidentiality of information received in confidence is to be protected..$^{33}$

The Rulebook itself does not address conflict of interest but tasks the Committee to address the issue in the rules of procedure. ${ }^{34}$ For this purpose, it will be important to formulate clear rules to ensure that members and alternates disclose any interest in a

\footnotetext{
${ }^{28}$ Ibid., Annex, para 5.

${ }^{29}$ Ibid., Annex, paras 15 and 16. The only other constituted bodies under the climate change regime with operational voting rules are the Compliance Committee, and the Executive Board of the Clean Development Mechanism, both under the Kyoto Protocol.

${ }^{30}$ Ibid., Annex, para 14.

${ }^{31}$ Ibid., Annex, para 13.

32 Ibid., Annex, paras 17 and 18

${ }^{33}$ Ibid., Annex, para 14

${ }^{34}$ Ibid., Annex, para 18
} 
matter under discussion that may constitute a conflict of interest or be incompatible with the requirements of independence and impartiality. For example, the rules should establish that a member from a party whose issue is before the Committee recuses himself or herself from further engagement with that matter.

Eighth, the rules of procedure to be developed by the Committee 'will be informed by the principles of transparency, facilitation, ... non-adversarial and non-punitive function, and pay[] particular attention to the respective national capabilities and capacities of Parties ${ }^{35}$ and to any other matters 'necessary for the proper and effective functioning' of the Committee's work. ${ }^{36}$ During the negotiations in Katowice there was a clear sense that the negotiators should not micromanage the Committee but instead allow it considerable discretion in designing its procedures. As the first members and alternates will be elected at CMA 2, the parties agreed that the Committee will develop the rules of procedure during 2020 and recommend them to CMA 3 for adoption. ${ }^{37}$

The rules of procedure will address the role of the Committee co-chairs, conflict of interest, any additional timelines and procedural stages, as well as reasoning in the Committee's decisions. ${ }^{38}$ However, these aspects are not exclusive. Any matters necessary for the proper and effective functioning of the Committee should be addressed. The necessary elements, for which details are still missing include: ${ }^{39}$

1. Further institutional arrangements, such as starting dates of terms of service for members and alternates, voting rights for alternates (i.e. only when serving as members), oath of service, agenda setting for meetings, notification of members and

\footnotetext{
35 Ibid., Annex, para 17.

${ }^{36}$ Ibid., Annex, para 18.

37 Ibid., Annex, para 17

${ }^{38}$ Ibid., Annex, para 18.

${ }^{39}$ See e.g, Kyoto Protocol, Decision 4/CMP.2, 'Rules of procedure' of the Compliance Committee of the Kyoto Protocol, FCCC/KP/CMP/2006/10/Add.1 (2007), available at

https://unfccc.int/resource/docs/2006/cmp2/eng/10a01.pdf; as well as the Rules of procedure of the Compliance Committee of the Kyoto Protocol (informal consolidated version) (3 February 2014), available at

https://unfccc.int/files/kyoto_protocol/compliance/application/pdf/consolidated_rop_with_cmp_4\&cmp9 amend 2014feb03.pdf. See also Working Arrangements on conflict of interest (Kyoto Protocol, Annual report of the Compliance Committee to the Conference of the Parties serving as the meeting of the Parties to the Kyoto Protocol, FCCC/KP/CMP/2010/6 (2010), available at https://unfccc.int/sites/default/files/resource/docs/2010/cmp6/eng/06.pdf), and time frames and contact with Parties (Kyoto Protocol, Annual report of the Compliance Committee to the Conference of the Parties serving as the meeting of the Parties to the Kyoto Protocol, FCCC/KP/CMP/2011/5 (2011), available at https://unfccc.int/resource/docs/2011/cmp7/eng/05.pdf).
} 
alternates, and arrangements for privileges and immunities for members and alternates ${ }^{40}$.

2. Further detail on initiation and process, for example, guidelines for the calculation of time periods, or for submissions by parties, or for the support by the secretariat; guidance for expert advice and for obtaining additional information from representatives of relevant bodies and arrangements under the Agreement; working arrangements for public participation; the details for issuing fact findings; sources and processes for the identification of systemic issues, the procedures for electronic decision making, for reasoning in decisions of the Committee, confidentiality, in particular of information received in confidence, access to sources of information, working language and the need for translations and interpretations, as well as the need for definitions and clarifications.

3. More detailed elaboration of measures and outputs, in particular, the content and process for the development of an action plan, on how to assist the party concerned in engaging with the support arrangements under the Agreement, the type of recommendations that could be given to the party concerned, or the process for the communication of recommendations to relevant bodies and arrangements. Particular attention will need to be applied to the elaboration of timelines related to the Committee's work. This includes timelines for the Committee to respond to requests for initiation of procedures (either by a party or by the CMA). It also relates to possible deadlines and 'grace periods,' when they are not provided for in the Agreement or the Rulebook, for the failure to submit mandatory information or a report under Mode 2 of initiation (see discussion in Section 6, below). Other aspects with regard to timelines relate to the determination to consult with parties, setting deadlines and/or grace periods for parties to respond to questions by the Committee, or the timelines for the development of an action plan according to paragraph 30(d) of the modalities and procedures. Importantly, the Committee at all stages shall pay particular attention to the respective national capabilities and circumstances of Parties, recognizing the special circumstances of the least developed countries and small island developing states. Moreover, the Committee will need to elaborate how to accord flexibility with regard to timelines as may be needed by Parties, paying attention to their respective capabilities and circumstances. ${ }^{41}$

\footnotetext{
${ }^{40}$ On the issue of privileges and Immunities, see René Lefebre and Sebastian Oberthuer, 'Key Features of the Kyoto Protocol's Compliance System', in Brunnée et al. 2012, supra note 3, 77-101. For the discussion of privileges and immunities for members of the CDM Executive Board, see Charlotte Streck and Jolene Lin, 'Making Markets Work: A Review of CDM Performance and the Need for Reform', 19(2) The European Journal of International Law 409 (2008).

${ }^{41}$ A15 MP, supra note 6, Annex, para 26.
} 
Overall, the Committee's institutional arrangements are designed in such a way as to provide for the legitimacy, continuity, stability, and predictability of its activities. While other of the Agreement's institutions and procedures have a role to play in encouraging parties to implement the Agreement and holding them accountable for their

performance, none has the mandate or capacity to engage with a party over a period of time to help resolve an issue. By comparison, the TER Teams are significantly smaller, and their engagement with a party ends with the publication of a technical expert review report (TER Report). ${ }^{42}$ The Facilitative Multilateral Consideration of Progress (FMCP), established under Article 13, is a plenary dialogue among party representatives consisting of a biennial, one-off question and answer session and a working group session. ${ }^{43}$ Article 14's Global Stocktake (GST) is to focus on the collective, rather than individual performance of parties, and is a year long technical dialogue, assisted by a joint SBI/SBSTA contact group, which takes place every fifth year. Its aim is to collect and technically assess information. The outcome is limited to a discussion of the findings with a view to informing parties in updating and enhancing, in a nationally determined manner, their actions and support. The GST will not engage with or facilitate the performance of individual parties.

The Article 15 Committee is therefore 'one of its kind' in the architecture of the Agreement. Its operation may become an important cornerstone of the Agreement's legitimacy, effectiveness and longevity.

\section{Committee Measures With Respect to a Party's Implementation or Compliance}

Paragraph 30 of the modalities and procedures provides the Committee with a toolbox of measures and outputs. ${ }^{44}$ Before exploring how these could be applied, we address two general aspects of that provision. First, does paragraph 30 provide an exhaustive list of the measures that the Committee may take? It states that the Committee 'shall take appropriate measures'; however, it also says that 'these may include the following'. Therefore, the Committee may not be limited to the listed measures, or it may not be required to take any of the listed measures. Furthermore, it could choose a combination of measures. There is no apparent hierarchy or sequence to follow, as long as the Committee considers that the measure is appropriate. Nevertheless, the negotiating history of paragraph 30 shows that its list was narrowed down from a much longer set which included, for example, early warnings, declarations of non-compliance, and measures related to Article $6 .{ }^{45}$ The shortening of the list to the current five options

42 A13 MPG, supra note 22, Annex, paras 187 and 188.

43 Ibid., Annex, paras 191-199.

44 A15 MP, supra note 6, Annex, para 30.

${ }^{45}$ See e.g. Informal Note by the Co-facilitators, Draft elements for APA agenda item 7: Modalities and procedures for the effective operation of the committee to facilitate implementation and promote compliance referred to in Article 15.2 of the Paris Agreement (13 November 2017), available at https://unfccc.int/process/bodies/subsidiary-bodies/ad-hoc-working-group-on-the-paris-agreementapa/information-on-apa-agenda-item-7. 
suggests that the parties were unable to agree on those other proposals. The Committee would therefore need to be cautious in deciding on an appropriate measure, considering that any application of measures that parties were unable to agree on during the negotiations might create controversy.

Second, while the Committee enjoys the discretion to choose an appropriate measure in each case, its decision shall be informed by the legal nature of the relevant provisions of the Agreement and the comments received from the party concerned, and it shall pay particular attention to the national capabilities and circumstances of the party concerned. Special circumstances of SIDS and LDCs, as well as situations of force majeure, are also to be recognized, where relevant. ${ }^{46}$ The Committee may also consider capacity constraints and needs or challenges, including in relation to support received. ${ }^{47}$

We will now examine the five measures listed in paragraph 30 in detail. Under clause (a) of the paragraph, the Committee may engage in a dialogue with the party concerned to identify the challenges faced, make recommendations, or share information, including on accessing support. In this case the Committee is working with the party, as a source of advice and assistance, trying to identify the implementation or compliance problem and help the party overcome it.

Clauses (b) and (c) of paragraph 30 are related to the finance, technology, and capacitybuilding bodies or arrangements under (or serving) the Paris Agreement. ${ }^{48}$ The relationship of the Committee to such supporting institutions was heavily debated during the negotiations. Some argued that, in order to facilitate implementation, it would be important for the Committee to help the party access financial, technological, or capacity-building support in those cases where implementation or compliance issues had arisen due to a lack of capacity or support. ${ }^{49}$ Others were concerned that the Committee would interfere with, assert authority over, or duplicate, the work of those supporting institutions. ${ }^{50}$ Another concern was the possibility that linking of non-

\footnotetext{
46 A15 MP, supra note 6, Annex, para 28.

${ }^{47}$ Ibid., Annex, para 29.

48 Which bodies and arrangements these are would need to be elaborated by the committee in its rules of procedure. Potentially, they may include as the Green Climate Fund, Global Environment Facility, Least Development Countries Fund, Special Climate Change Fund, Adaptation Fund, Standing Committee on Finance, Technology Executive Committee, Climate Technology Center and Network, and Paris Committee on Capacity Building. See PA, art. 9.8, art. 10.3, and Decision 1/CP.21, supra note 5, paras $58,59,63,71$.

${ }^{49}$ See e.g. LMDC Submission on modalities and procedures for the effective operation of the Article 15 Committee to facilitate implementation and promote compliance (30 September 2017), available at https://unfccc.int/process/bodies/subsidiary-bodies/ad-hoc-working-group-on-the-paris-agreementapa/information-on-apa-agenda-item-7/submissions-received-on-apa-item-7.

${ }^{50}$ See e.g. Australian submission on modalities and procedures for the effective operation of the Article 15 Committee (13 April 2017), available at https://unfccc.int/process/bodies/subsidiary-bodies/ad-hocworking-group-on-the-paris-agreement-apa/information-on-apa-agenda-item-7/submissions-received-onapa-item-7.
} 
implementation or non-compliance to support might create a perverse incentive for parties. ${ }^{51}$ The current text reflects a compromise. Under clause (b) the Committee could assist the party concerned in the engagement with the supporting institutions, make a recommendation to the party concerned and communicate that recommendation to the relevant bodies or arrangements. The text clarifies that the Committee is not in a superior position to other bodies or arrangements, but engages the party concerned in a dialogue in order to identify possible challenges and solutions. It will not be able to do the substantial work that might duplicate the work of other bodies and arrangements. In a nutshell, it is to play a facilitative role between the party and the supporting institutions. The Committee may need to develop more precise guidelines on how this will be done. Whether it will be able to assist the party concerned in practical terms remains to be seen.

Under paragraph 30 clause (d) the Committee may recommend the development of an action plan. There are similar measures in other MEA mechanisms. ${ }^{52}$ The text suggests that the Committee would recommend the development of an action plan and the party concerned would develop the plan itself, although it may ask the Committee for assistance with it. Earlier text had suggested that the Committee could request a plan including a description of the implementation challenges or causes of non-compliance, a description of measures that the party intends to take, and a timeline for the measuresbut those details were not agreed. ${ }^{53}$ The Committee will need to revisit the characteristics of the action plan, perhaps during the development of the rules of procedure.

Paragraph 31 encourages a party that has developed an action plan pursuant to clause 30 (d) to inform the Committee on progress it has made in implementing the plan. ${ }^{54} \mathrm{~A}$ more proactive role for the Committee in following up on action plans was proposed, ${ }^{55}$ but not agreed to, out of concern that it would intrude on state sovereignty.

Paragraph 30(e) mandates the Committee to issue findings of fact. While the Committee may take the previous four measures under all three initiation modes, paragraph 30(e)

\footnotetext{
${ }^{51}$ Meinhard Doelle, 'Compliance in Transition: Facilitative Compliance Finding its Place in the Paris Climate Regime' 12(3) Carbon \& Climate Law Review 229 (2018), 236.

52 For example, the committee for promoting implementation and compliance of the Basel Convention could elaborate, as appropriate and with the cooperation of parties, voluntary compliance action plans, para 19(c), Decision VI/12; the compliance committee under the Cartagena Protocol on Biosafety could 'Request or assist, as appropriate, the Party concerned to develop a compliance action plan...', para VI 1(c), Decision BS-I/7.

${ }^{53}$ See e.g. Ad-hoc Working Group on the Paris Agreement, Revised additional tool under item 7 of the agenda (8 September 2018), available at

https://unfccc.int/sites/default/files/resource/Final\%20iteration_APAitem7Tool_2018.09.08.pdf (hereinafter A15 revised additional tool).

${ }^{54}$ A15 MP, supra note 6, Annex, para 31

55 Ibid.
} 
applies only to the matters referred to in paragraph 22(a). ${ }^{56}$ This could be seen as a reflection of the views of some parties that the Committee should be able to take this measure only with regard to promoting compliance with the mandatory, treaty-based provisions referred to in paragraph $22(\mathrm{a}) .^{57}$

Paragraph 30(e) was heavily debated during the negotiations. An earlier version included such proposals as sending a warning, issuing a statement of non-compliance, and measures related to the Article 6 mechanism. ${ }^{58}$ However, there was concern that such measures would be punitive and therefore inconsistent with the facilitative nature of Article 15. ${ }^{59}$ The compromise is a more neutral outcome. Because paragraph 30(e) refers exclusively to cases initiated under paragraph 22(a), any finding of fact would relate to the readily identifiable circumstances of non-compliance with a binding obligation, such as the non-submission of a report, listed in that paragraph. In this context, such a finding would lead to the logical conclusion that the party was in noncompliance, but without a formal finding of non-compliance by the Committee.

Paragraph 30(e) refers to 'matters' referred to in paragraph 22(a). While this includes cases initiated under Mode 2, and appears to exclude cases initiated under Mode 3, which covers different 'matters', it does not necessarily exclude cases initiated under Mode 1 (self-referral), which covers 'the provisions' of the Agreement. The provisions would include the 'matters' of paragraph 22(a). This reading avoids the situation where a party self-initiates under paragraph 20 with regard to a matter listed in paragraph 22(a) in order to avoid the possibility of the Committee making a finding of fact. According to this reading, the particularity of paragraph 30 (e) is not based on the mode of initiation but on the legal nature of the provisions concerned.

Finally, paragraph 30(e) does not specify the addressee of the findings of fact. While the measures included in clauses (a)-(d) of paragraph 30 are addressed to the party concerned, the Committee could issue findings of fact in various ways. 'Issuing' could, for example, take the form of a public statement, or a letter to the party, or be included in the annual report to the CMA, or a combination of the above. This step remains to be clarified.

We conclude that the Rulebook provides the Committee with a set of tools to facilitate implementation and promote compliance without duplicating the work of other bodies

\footnotetext{
${ }^{56}$ Ibid., Annex, para 30(e).

${ }^{57}$ See e.g. Submission of Norway on APA item 7 (6 April 2017), available at https://unfccc.int/process/bodies/subsidiary-bodies/ad-hoc-working-group-on-the-paris-agreementapa/information-on-apa-agenda-item-7/submissions-received-on-apa-item-7. ${ }^{58}$ See e.g. A15 revised additional tool, supra note 53.

59 See e.g. Submission by The Kingdom of Saudi Arabia on behalf of The Arab Group to the Ad Hoc Working Group on the Paris Agreement ('APA') on Agenda item 7 (30 March 2017), available at https://unfccc.int/process/bodies/subsidiary-bodies/ad-hoc-working-group-on-the-paris-agreementapa/information-on-apa-agenda-item-7/submissions-received-on-apa-item-7.
} 
or arrangements under the Paris Agreement. The guidance on those tools is still limited and the Committee through its practice, or in its rules of procedure, or by adopting working arrangements, will need to develop a clearer understanding on how it can effectively use measures to facilitate implementation and promote compliance.

\section{Initiation Mode 1 under paragraph 20}

Under Mode 1 (paragraph 20) a party may make a written submission to the Committee with respect to its own implementation 'and/or' compliance. Several questions arise. First, what is the rationale for including self-initiation? This was not a contentious issue among parties, and it was included in the text at an early stage of the negotiations. ${ }^{60}$ This mode of initiation is common in many compliance mechanisms in MEAs. ${ }^{61}$ This reflects an understanding that the compliance mechanisms in MEAs are different from the traditional, adversarial dispute settlement mechanisms in international law. ${ }^{62}$ Unlike traditional dispute settlement mechanisms, MEA compliance mechanisms emphasize non-confrontational facilitation, promoting implementation and compliance, and preventing non-compliance. ${ }^{63}$ Focusing on preventing non-compliance makes sense for MEAs as it is in the common interest to prevent environmental harms as they are usually difficult to repair and restore afterwards. Moreover, non-compliance with MEAs can be due to a lack of capacity instead of a lack of will, particularly among developingcountry parties. ${ }^{64}$ If compliance mechanisms can help provide assistance on implementation or compliance, the ultimate objective of the treaty will be served. For this reason, parties are given the opportunity to bring challenges they face to the attention of the Committee.

Second, the scope of Mode 1 covers matters related to 'any' provisions of the Paris Agreement related to party's own implementation or compliance. It is not limited to

\footnotetext{
${ }^{60}$ See Informal note by the Co-facilitators (7 May 2017) where the committee activity may commence by the party concerned. See also Preliminary material in preparation for the first iteration of the informal note (9 November 2017) where the initiation of consideration has two options: self-referral only and selfreferral and other means of initiation. Both are available at https://unfccc.int/process/bodies/subsidiarybodies/ad-hoc-working-group-on-the-paris-agreement-apa/information-on-apa-agenda-item- 7 .

${ }^{61}$ See e.g. Decision IV/5: Non-compliance procedure (1992) of the Montreal Protocol on Substances that Deplete the Ozone Layer, available at https://www.informea.org/en/decision/decision-iv5-noncompliance-procedure\#decision-body-field, Annex IV, para 4; Decision VI/12, Establishment of a mechanism for promoting implementation and compliance (2002), the Basel Convention on the Control of Transboundary Movements of Hazardous Wastes and their Disposal, available at

https://www.informea.org/en/decision/establishment-mechanism-promoting-implementation-andcompliance (hereinafter Basel Convention Decision VI/12), para 9(a).

${ }^{62}$ See e.g. the dispute settlement provision under the PA, supra note 5, art. 24, and art. 14.

${ }^{63}$ Nils Goeteyn and Frank Maes, 'Compliance Mechanisms in Multilateral Environmental Agreements: An Effective Way to Improve Compliance?', 10(4) Chinese Journal of International Law 791 (2011), 800 .

64 Ibid., 799
} 
mandatory provisions; neither does it cover another party's performance. Thus, both 'shall' and 'should' provisions, such as the submission and update of an adaptation communication or the formulation and communication of a long-term low greenhousegas emission development strategy, can be raised by a party with respect to itself to the Committee. Although it refers to 'all' provisions, Mode 1 does not cover provisions that an individual party could not implement or comply with, for example those that set out the mandate of an institution.

Third, what safeguards ensure that self-initiation will be utilized in good faith, so that the Committee is not overloaded with submissions unrelated to issues of implementation or compliance with provisions of the Agreement? The Committee is to make a preliminary examination of the submission to verify that it contains 'sufficient' information, including on whether the matter relates to the party's own implementation of, or compliance with, a provision of the Agreement. ${ }^{65}$ While the Rulebook doesn't describe the outcome of this preliminary examination, it iis reasonable to conclude that that the Committee has the discretion not to consider a matter if the information provided by the party is insufficient, or ask the party to provide more information or clarification. The timeline for this process will be elaborated in the Committee's rules of procedure

Other safeguards were discussed but not agreed to. These included a showing that the party concerned had first exhausted its efforts to seek assistance with implementation or compliance through other Paris Agreement bodies or arrangements, as well as criteria to assess whether the submission is de minimis or ill-founded. Because the adopted rule allows the Committee to 'verify that the submission contains sufficient information', 66 some of the latter concerns appear to be addressed.

\section{Initiation Mode 2 under paragraph 22 (a)}

\subsection{Rationale of Committee Initiation}

During the negotiations, parties recognized the necessity of other modes of initiation. Various options were on the table, including party-to-party initiation, Secretariat initiation, CMA initiation, and initiation by other bodies, including TER Teams. ${ }^{67}$ Party-to-party initiation seemed overly adversarial, Secretariat initiation threatened that body's neutrality, CMA initiation was considered more appropriate for systemic issues (see section 8, below), and TER Team initiation was thought to put at risk the technical nature of those teams. In light of those concerns, the approach of enabling the Committee itself to initiate cases was chosen.

\footnotetext{
65 A15 MP, supra note 6, Annex, para 21.

${ }^{66}$ Ibid., Annex, para 21.

${ }^{67}$ See e.g. A15 revised additional tool, supra note 53.
} 


\subsection{Scope of Mode 2}

The negotiators weighed multiple options for defining the scope of Mode 2 initiation. One approach would be to base the scope on the characteristics of the provisions, taking either a broad scope consisting of all legally binding, 'shall', provisions, or a narrow scope limited to legally binding, objectively assessable, provisions applicable to parties individually. ${ }^{68}$ This approach would require the Committee to exercise some judgment as to which provisions fall within the broad or narrow category. Another approach would be to define scope by listing provisions, either by article number or description of the subject matter. ${ }^{69}$ The first approach was proposed by parties favouring dual functions for the Committee (one focused on implementation, the other on compliance), with initiation by Committee being reserved for the function of promoting compliance related to the mandatory provisions of the Agreement. ${ }^{70}$ The second approach had two rationales. The first was to reassure parties through identification of the exact provisions on which the Committee could act. This would avoid inefficient and controversial debates among the Committee members over which provisions were within its scope. ${ }^{71}$ The second rationale was to ensure that the Committee could take up issues of implementation or compliance that would not be reviewed by the ETF, and thus be complementary to the ETF. ${ }^{72}$

The agreed outcome on Mode 2 follows the second approach, listing four key mandatory procedural obligations in the Agreement. ${ }^{73}$ Compliance with each of these can be identified from public sources of information provided for under the Agreement, which assures parties that only information available through those sources will be the basis of initiation.

Does the paragraph 22(a) list include all the uncontroversially binding provisions of the Agreement? A reading of the Agreement suggests that some gaps exist. For example, Article 4.8, on providing information for clarity, transparency, and understanding of NDCs; Article 4.13, on accounting for NDCs; and Article 6.2, on avoiding doublecounting, are uncontroversially binding obligations for individual parties but are not explicitly referred to in paragraph 22(a). Also not included is the commitment, in Article 4.2 (second sentence), to pursue domestic mitigation measures, which is

\footnotetext{
${ }^{68}$ A distinction can be made, for example, between an 'individual' obligation that 'each party shall' as compared to a 'collective' obligation that 'developed country parties shall.'

${ }^{69}$ See e.g. A15 revised additional tool, supra note 53.

${ }^{70}$ See e.g. AILAC Submission, supra note 13.

${ }^{71}$ As the debate on the scope of the committee initiation took place at a rather late stage of the negotiations, some of the concerns and rationale for the choice of approach were not reflected in the two rounds of written submissions of parties in 2017 but were made by parties orally in general.

72 See e.g. Submission of Malta on behalf of European Union on Article 15 mechanism (21 March 2017), available at https://unfccc.int/process/bodies/subsidiary-bodies/ad-hoc-working-group-on-the-parisagreement-apa/information-on-apa-agenda-item-7/submissions-received-on-apa-item- 7 .

3 A15 MP, supra note 6, Annex, para 22(a).
} 
considered by some as a binding obligation, but more difficult to track and judge. Does the Mode 2 list consist of provisions that will not be reviewed by the ETF? Yes, because they are either outside the scope of the TER Teams' mandate (failure to communicate an NDC; review of reports under Article 9.5) or a party's failure to comply would prevent the TER Teams from operating (failure to communicate a Biennial Transparency Report-BTR). However, on this point too the Mode 2 list is not exhaustive as well. As noted, it does not include compliance with Article 4.8, on NDC information, or the more contentious collective financial obligations in Article 9.1 and 9.3. These considerations show that the proposed rationale by parties does not fully explain the current list in paragraph 22(a). A more appropriate explanation is that the list reflects what the CMA was able to agree to as the binding provisions that the Committee must address, taking into account the political nature of the negotiations.

\subsection{Content of Mode 2}

Paragraph 22(a) requires the Committee to initiate its work in the circumstances of the listed cases as a matter of course (we use the word 'automatically' to characterize this mode). However, to better understand how this will happen requires a careful reading of the four triggering situations.

Under clause (i) of paragraph 22(a), the Committee will initiate a case where a party has not communicated or maintained its NDC, based on the status of the party's communication in the public registry of NDCs. Mode 2 matters concern only the procedural obligation to communicate and maintain an NDC, not questions of implementation or achievement. Although the word 'maintain' might be interpreted as something more than a procedural obligation, when read together with paragraph 23 of the modalities and procedures, it is clear that Committee will not address the content of an NDC. Thus 'maintain' here means that a party must ensure that it always has an NDC in the registry, effective during the current time period.

Under clause (ii) of paragraph 22(a), the Committee will initiate a case where a party has not submitted a mandatory report or communication under Article 13, paragraph 7 or 9, or under Article 9.7-a BTR. Cases under this clause will cover the Article 13.7(a) obligation of each party to provide a national inventory report; the Article 13.7(b) obligation to provide information necessary for tracking progress made in implementing and achieving a party's NDC; ${ }^{74}$ and the obligation of developed countries to provide information on financial, technology-transfer, and capacity-building support provided to developing countries (Article 13.9 and 9.7). ${ }^{75}$ As provided for in paragraph 23, the question is only whether the party submitted the relevant report or communication, it

\footnotetext{
${ }^{74} \mathrm{PA}$, supra note 5 , art. 13 , para 7 .

${ }^{75}$ Ibid., art. 13, para 9; art. 9, para 7.
} 
does not go to the content or quality of the information. In order to verify a party's compliance with these Articles, presumably the Committee will look at the online BTR portal maintained by the Secretariat, as established by CMA $1 .^{76}$

Similarly, under clause (iv) of paragraph 22(a), the Committee will only address whether a party has communicated biennial indicative information on projected finance under Article 9.5 of the Paris Agreement, not the content of that information.

'Mandatory' makes clear that the Committee will only look at the obligation of developed-country parties, not other parties. The online portal for posting and recording the biennial communications, established by CMA 1 and maintained by the Secretariat, will no doubt serve as a source of evidence on whether to initiate a case. ${ }^{77}$

Under clause (iii) of paragraph 22(a), the Committee will initiate a case when a party has not participated in the FMCP, based on information from the Secretariat. The FMCP consists of a written question-and-answer phase and a working group session phase. ${ }^{78}$ Failure of a party to provide written answers or be present at the working group session will lead to Committee initiation. It is worth noting that even where a party fails to submit a BTR, the Secretariat will still arrange for an FMCP for the party. ${ }^{79}$ Thus the Committee's intervention may be triggered under both clauses (ii) and clause (iv) separately.

\subsection{The Timeline Question}

A remaining challenge for the Committee in addressing Mode 2 cases is to know the timelines for the relevant procedural obligations so as to know when a violation occurs in order to initiate a case. This issue was briefly discussed during the negotiations but left unresolved. An examination of relevant COP/CMA decisions suggests that some timelines, and the flexibility allowed for them, has already been defined. For NDC communication, Decision 1/CP.21 provides that parties are to submit their NDC at least 9 to12 months prior to the 'relevant session' of the CMA. ${ }^{80}$ This allows a three-month margin for the submissions, and the exact dates will become apparent once the CMA has agreed on a date for the relevant session. For the submission of a mandatory report or communication under Article 13, paragraphs 7 and 9, the ETF decision provides that the first BTR is to be submitted no later than 31 December $2024 .{ }^{81}$ This is a clear deadline. Although the decision does not provide a timeline for subsequent reports,

\footnotetext{
76 A13 MPG, supra note 22, Annex, para 15.

${ }^{77}$ Paris Agreement, Draft Decision -/CMA.1, Identification of the information to be provided by Parties in accordance with Article 9, paragraph 5, of the Paris Agreement, FCCC/CP/2018/L.15 (2018) (hereinafter A9 Fin Info), available at https://unfccc.int/node/184648, para 6.

78 A13 MPG, supra note 22, Annex, paras 191-196.

79 Ibid., para 198.

${ }^{80}$ Decision 1/CP.21, supra note 5, para 25

81 A13 MPG, para 3.
} 
'biennial' implies a report deadline every second year thereafter. For the submission of Article 9.5 information, the window for the first submission opens 'starting in 2020' and presumably closes at the end of that year. ${ }^{82}$ These reports are biennial for developedcountry parties.

The timing of the FMCP depends on the BTR and TER Report. A FCMP will be arranged 'as soon as possible' after the TER Report is available. ${ }^{83}$ In the absence of a TER Report within 12 months after submission of a BTR, the Secretariat will make arrangements for the party to participate in a FMCP at the next available opportunity. If a Party does not submit a BTR within 12 months after it iss due, the Secretariat will make arrangements for the party to participate at a FMCP at the next available opportunity. ${ }^{84}$ In all three cases, once the date has been set, non-engagement of the party in the question and answer phase or working group session phase will lead to a Mode 2 case.

For these procedural obligations, then, the decisions provide mainly margins with end dates rather than fixed deadlines. The Committee will presumably begin to engage the party concerned once that end date has passed. How quickly it will do so will depend on the timing of its meetings or inter-sessional work. The committee is expected to develop a clearer guidance on the timeline criteria through its practice and in the rules of procedure. ${ }^{85}$

\subsection{Is the mode of initiation a measure in itself?}

As illustrated above, all the five measures under paragraph 30 could apply to a Mode 2 case. However, because a Mode 2 case is initiated only in a circumstance in which a party has demonstrably failed to comply with one of the listed obligations, the question arises as to whether a 'finding of fact' to this effect will result in every such case.

Although the answer seems to be yes, it is important to bear in mind that the Committee is mandated to take 'appropriate' measures with a view to facilitating implementation and promoting compliance, and that it shall pay particular attention to the national capabilities and circumstances of the party concerned in identifying those measures. In this situation, the Committee will need to exercise its discretion and can be expected to take into account the length of a party's delay in meeting a timeline, the willingness of the Party to cooperate with the Committee and subsequent efforts to implement the obligation.

\section{Initiation Mode 3 under paragraph 22 (b)}

\footnotetext{
${ }^{82}$ A9 Fin Info, supra note 77,Annex, para 4.

83 A13 MPG, Annex, para 197.

${ }^{84}$ Ibid., Annex, para 198.

${ }^{85}$ A15 MP, Annex, paras 17 and 18.
} 
Under paragraph 22(b), the Committee may initiate cases in a way that complements the rules, procedures, and institutions of the ETF. As explained earlier, this will allow it to backstop the oversight of a party's performance on the MPGs under the ETF in circumstances where issues raised by the TER Teams have been left unresolved.

The roles of the TER Teams and of the Committee are designed to be complementary in both helping parties and holding them accountable for their individual performance. The purpose of the ETF includes the tracking of progress toward achieving parties' NDCs and providing clarity on support provided and received by parties. ${ }^{86}$ To this end, each party is to submit, biennially, national inventory reports and information necessary to track its NDC progress. ${ }^{87}$ Moreover, developed country parties shall (and other parties that provide support should) submit information on support provided to developing countries to implement the Agreement. ${ }^{88}$

Each party's information, communicated in the form of a BTR, is to undergo a technical expert review carried out by an ad hoc TER Team composed by the secretariat from a roster of experts. ${ }^{89}$ The TER Team will review the consistency of the information provided with the ETF's MPGs. With regard to the 'shall' provisions in the MPGs, the TER Team will identify any 'areas of improvement' in the form of 'recommendations' and include these in its final report. ${ }^{90}$ The reports will be published on the Secretariat website. $^{91}$ The TER Teams therefore have a role in holding parties accountable for providing the information necessary to track progress with their core commitments, consistent with the MPGs. They can also provide assistance to parties in improving their performance and in identifying capacity-building needs. ${ }^{92}$

During the negotiations, many parties were uncomfortable with making a link between the ETF and Article 15 processes. ${ }^{93}$ Some were of the view that a TER Team's engagement with a party would provide enough assistance and incentive to ensure that the party implements the MPGs. Some were concerned that strengthening the link between Article 15 and the ETF would raise sovereignty issues and lead to a weakening of the mandatory character of the ETF's MPGs as well as to a less rigorous TER. Others yet were concerned that linking the two processes could undermine the technical and apolitical nature of the TER Teams' role. In particular, they worried that technical experts would be hesitant to identify 'areas of improvement' if this were seen as

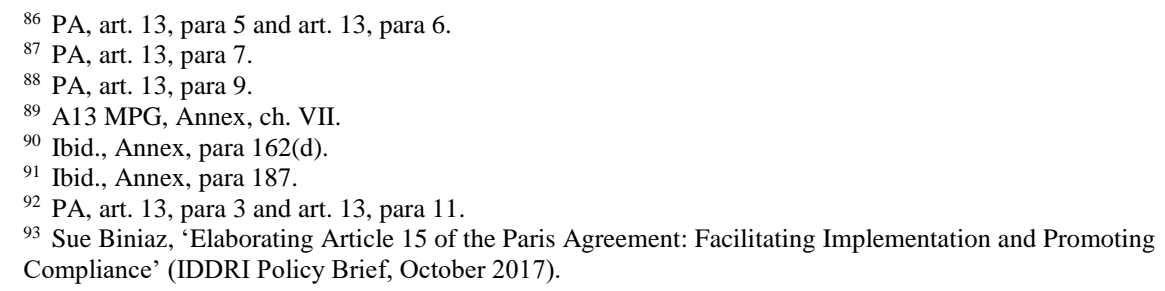


triggering the Article 15 Committee. ${ }^{94}$ Still other parties felt it essential that the ad hoc TER Teams needed to be backstopped by the standing Committee, particularly where a TER Team's engagement with a party did not resolve a performance problem. Finding common ground required coming to an understanding between parties as well as within delegations, as some ETF and Article 15 negotiators belonging to the same party disagreed with each other on these questions. ${ }^{95}$

In the end a balance was struck that enables the Committee to take up issues unresolved by the TER Teams, but limits the scope of the Committee's role in several important respects. Under paragraph 20(b), the Committee may, at its discretion, and with the consent of the party concerned, engage that party in cases of 'significant and persistent inconsistencies' between the information that the party has submitted under the ETF and the ETF MPGs.

In order for such a case to be taken up by the Committee, a TER Team must have included in its final report a 'recommendation' related to an 'area of improvement' of the party's performance on the ETF's MPGs (the 'shall' provisions only). It is important to note that Article 13 limits the scope of TER Team review, and therefore also limits the Committee's Mode 3 review to information provided under Article 13. ${ }^{96}$ Most of the ETF's MPGs are 'shalls' and generally are expressed in mandatory terms when they implement a mandatory treaty-based reporting obligation in the Agreement. So, for example, each party 'shall' provide information necessary to track progress under Article 13.7(b) of the Agreement: the corresponding MPGs are 'shall' provisions. ${ }^{97}$ In parallel, the MPGs associated with the Agreement's 'encouragement' to countries (other than developed country parties) to provide support are expressed as 'should' provisions $^{98}$ and will result in neither a TERT recommendation nor a Mode 3 case.

94 This concern was derived in part from the experience of the Kyoto Protocol Compliance Committee, which can be triggered by the identification by an expert review team of a 'question of implementation.' See, for example, Jutta Brunnée, Multilateral Environmental Agreements and the Compliance Continuum' in: Gerd Winter (ed.) TRANSNATIONAL GOVERNANCE OF ENVIRONMENTAL CHANGE, Cambridge University Press, 2005, pp 387; also Meinhard Doelle, Experience with the Facilitative and Enforcement Branch of the Kyoto Compliance System', in Brunnée et al. 2012, supra note 3, pages 201-1221.

95 See for a discussion of the link between Article 13 and 15: Sue Biniaz, supra note 93, available at: https://www.iddri.org/en/publications-and-events/policy-brief/elaborating-article-15-paris-agreementfacilitating.

${ }^{96}$ For example, the MPGs exclude from TERT review and recommendations (and therefore from the scope of the Committee) provisions related to the description of the NDC (A13 MPG, paras 149(b) and 64).

97 A13 MPG, Annex, ch. III.C.

98 A13 MPG, Annex, ch. V. 
To understand whether or how the Committee might take up a Mode 3 case requires analysis of the ETF's MPGs and the role of TER Teams in reviewing the MPG. ${ }^{99}$ For initiation, the Committee must decide whether the recommendation in the TER Team's report, together with any written comments provided by the party during the review, relate to a 'significant and persistent' inconsistency between the information submitted by the party and the ETF MPGs. The Rulebook does not define 'significant and persistent', but the language implies a judgment by the Committee on whether the inconsistency crosses a de minimis threshold and demonstrates the party's failure to respond to repeated efforts, presumably by the TER Team or the Secretariat, to encourage the party to improve its performance. 'Significant' indicates that the Committee is to act only on cases in which the inconsistencies significantly limit the effective functioning of the transparency framework, whether with regard to the party concerned or more generally. 'Persistent' may be taken to refer to circumstances where a party has failed to improve over time - for example, where an issue is unresolved after repeated TER cycles. The two threshold criteria will need to be further developed by the Committee through in its rules of procedure or its practice.

A Mode 3 case will move forward only with the consent of the party concerned. This was a compromise arising from the concern of some parties about intrusion on sovereignty. Yet Mode 3 initiation may provide a degree of accountability even if the party concerned ultimately withholds its consent. This partly depends on how the Committee's consideration of a case is sequenced and made public. Read together, paragraphs 22 (b) and 24 suggest that the process begins with a Committee decision to initiate consideration. It would make sense that this would involve a preliminary determination that a 'significant and persistent' inconsistency exists. The Committee will then notify the party and request it to provide information, including whether it consents to the case moving forward. If the preliminary stages of this process were to be made public, the party would face political pressure to engage with the Committee to provide its perspective on the issue, or even to benefit from whatever assistance the Committee can facilitate. Yet, to make the Committee's preliminary determination public might be seen as undermining the right of the party to withhold its consent. It could also be seen as running counter to Mode 3's emphasis on 'facilitative consideration', and, with regard to developing countries, to the references to 'support'

${ }^{99}$ For example, under para 6 of the A13 MPG those developing countries that exercise 'a flexibility' in the MPGs 'shall clearly indicate the provision to which flexibility is applied, concisely clarify capacity constraints . . . and provide self-determined estimated time frames for improvements provided for in relation to these constraints.' As this is a 'shall' provision in the MPGs, a TER Teams could make a recommendation, and the Committee might act on that recommendation. However, there might be doubt whether a recommendation on para 6 would amount to 'significant' inconsistency, which needs to be decided by the Committee in its future work. Meanwhile, para 6 clarifies that the TER Teams shall not review the substantive basis of the party's determination to apply such flexibility, nor its capacity to implement the provision without flexibility. In this context it seems that neither the TER Team nor the Committee will be in a position to second guess whether a developing country 'needs' a flexibility in light of its capacities. A13 MPG, Annex, para 149(e). 
and 'flexibilities' to be extended under Articles 13(14) and 15. If the preliminary determination is not made public, some pressure on the party would remain if the Committee included the fact that the party withheld its consent in its annual report to the CMA.

In the course of its engagement in a Mode 3 case, the Committee shall take appropriate measures, which may include the measures in paragraph 30 (discussed in section 4, above). In circumstances were the significant and persistent inconsistencies are due to gaps in the party's capacity, measures involving assistance in engaging with bodies that provide financial, technological, or capacity-building support may be of particular relevance. ${ }^{100}$ In circumstances where the inconsistencies have resulted from a lack of political attention, the Committee's initiation of a case may be enough to solve the problem by raising the profile of the issue before the party's authorities.

A key question on Mode 3, and on the Committee's utility more generally, is whether it will be able to call attention to circumstances where a party is off track in implementing, or has failed to achieve, its NDC. This aspect of accountability would seem to be important in creating an incentive for parties to achieve their NDCs. As discussed, under Article 13.7(b), each party is required to provide the information necessary to track progress made in implementing and achieving its NDC, and this will be reviewed by a TER Team. The Team has a mandate to conclude whether a party has provided the information required by the ETF's MPGs, including a self-assessment by the party on whether it has achieved its NDC. ${ }^{101}$ Based on this, it will likely be evident from the TER Team's final report whether the party has achieved its NDC. The Committee does not, however, have a mandate to make a formal finding on this issue. ${ }^{102}$

\section{Identifying and Addressing Issues of a Systemic Nature}

The Committee may, on its own initiative, identify and make recommendations to the CMA with regard to issues of a systemic nature. The CMA may also request the Committee to do the same. ${ }^{103}$ This form of initiation was inspired by similar practices

100 A15 MP, supra note 6, Annex, para 30(b) and (c); PA, supra note 5, art. 13, para 14 and art. 13, para 15; Decision 1/CP21, supra note 5, para 84, establishing a Capacity-building Initiative on Transparency to support developing countries in implementing the ETF.

101 A15 MP, supra note 6, Annex, para 70.

102 See Benoit Mayer, 'Transparency Under the Paris Rulebook: Is the Transparency Framework Truly Enhanced?' Climate Law [comment to editor: please .provide page number etc.]

103 A15 MP, supra note 6, Annex, paras 32-33. 
under other MEA mechanisms, such as the Basel Convention ${ }^{104}$ and the Minamata Convention. ${ }^{105}$

The rationale for this provision is that the Committee, over time, will be in a position to see certain recurring challenges faced by multiple parties. Giving its access to a wealth of information, and after working for a period of time, the Committee should be in a situation to identify these challenges and make recommendations to the CMA.

Systemic issues may include fundamental challenges to parties' implementation and compliance that are beyond the performance of individual parties and that may need to be addressed. Consideration of systemic issues might also lead to proposals to enlarging the scope of the Committee's work. While the modes of initiation discussed above address the performance of individual parties and are confined to a relatively small set of provisions, the scope of systemic issues could include all the provisions of the Agreement. ${ }^{106}$ Thus the consideration of systemic issues should help the Committee to make a wider and more comprehensive examination. This is another example of how the Committee could improve the effectiveness and efficiency of the Agreement.

The Committee can consider systemic issues in two ways. First, the CMA can ask the Committee to examine a systemic issue in the understanding that the CMA serves as the supreme body of the Agreement and is responsible for its overall implementation. ${ }^{107}$ Second, the Committee can itself identify an issue during its course of work and bring it and any recommendations to the attention of CMA. ${ }^{108}$ This ability to identify issues on its own gives the Committee a broader mandate than similar arrangements in other MEAs. ${ }^{109}$

The outcome of the two ways of consideration is similar. The Committee will report back and, where appropriate, make recommendations to the CMA in the first scenario and bring the issues and, as appropriate, any recommendations to the attention of the

\footnotetext{
104 In accordance with the terms of reference of the mechanism for promoting implementation and compliance of the Basel Convention, the Committee shall, as directed by the Conference of the Parties, review general issues of compliance and implementation under the Convention. Basel Convention Decision VI/12, supra note 61.

105 Art. 15, para 2 of the Minamata Convention on Mercury, available at

http://www.mercuryconvention.org/Portals/11/documents/conventionText/Minamata\%20Convention\%20 on\%20Mercury e.pdf, provides that 'the Committee shall examine both individual and systemic issues of implementation and compliance and make recommendations, as appropriate, to the Conference of the Parties.

106 See e.g. Submission of Maldives on behalf of AOSIS on article 15 mechanism (15 April 2017) and submission of Argentina on behalf of Argentina, Brazil and Uruguay on article 15 mechanism, (8 May 2017), both available at https://unfccc.int/process/bodies/subsidiary-bodies/ad-hoc-working-group-on-theparis-agreement-apa/information-on-apa-agenda-item-7/submissions-received-on-apa-item-7.

107 PA, supra note 5, art.16, para 4.

108 A15 MP, supra note 6, Annex, para 33.

${ }^{109}$ Under the Basel Convention, the general review of the committee will be taken under the direction of the conference of the parties, not by the committee itself.
} 
CMA for its consideration in the second scenario. ${ }^{110}$ Yet, the Committee can only make recommendations; any decision on how to address systemic issues would need to be taken by the CMA.

During the negotiations, some parties proposed that the outcome of the consideration of systemic issues could serve as the input of the GST. While this was not included in the final text, ${ }^{111}$ the GST will, in any case, have an open source of input of information, including from the Agreement's 'constituted bodies' which include the Committee. ${ }^{112}$

\section{Unfinished Business: The Role of the Committee in Overseeing Carbon Markets}

The use of international carbon markets (or 'cooperative approaches) poses particular challenges for tracking implementation and compliance because it depends on the performance of two or more parties. Accordingly, Article 6.2 of the Agreement recognizes that the 'international transfer of mitigation outcomes' will require robust reporting and accounting rules. Article 6.2 contains the legally binding obligation for each party participating in cooperative approaches 'to apply robust accounting to ensure, inter alia, the avoidance of double counting' of the same emissions reductions by more than one party. ${ }^{113}$ Such double counting is to be avoided on the basis of a corresponding adjustment by parties for emissions and removals covered by their NDC. ${ }^{114}$

This need for additional oversight of international carbon markets was earlier recognized in the design of the Kyoto Protocol, which entrusted its Compliance Committee to suspend and reinstate a party's ability to trade on the basis of whether it was in compliance with reporting and accounting rules. ${ }^{115}$ While the Agreement's approach to transactions of internationally transferable mitigation outcomes (ITMOs) under Article 6, paragraphs 1 and 2, is more decentralised than under the Kyoto Protocol, the Rulebook negotiations did contemplate a specific role for the Article 15 Committee in relation to markets. Indeed, the last drafts of the Article 15 rules contained a placeholder for a link to Article 6, which was only deleted towards the end

\footnotetext{
${ }^{110}$ A15 MP, supra note 6, Annex, paras 32 and 33.

111 See e.g. Draft text under item 7 of the agenda (first iteration, 4 December 2018), available at https://unfccc.int/process/bodies/subsidiary-bodies/ad-hoc-working-group-on-the-paris-agreementapa/information-on-apa-agenda-item-7.

${ }^{112}$ Decision -/CMA.1, Matters relating to Article 14 of the Paris Agreement and paragraphs 99-101 of decision 1/CP.21, FCCC/CP/2018/L.16 (2018), available at https://unfccc.int/node/187579, para 37.

113 A13 MPG, supra note 22, Annex, para 77(d)(ii).

114 Decision 1/CP.21, supra note 5, para 36.

115 See Francesco Sindico, 'Post-2012 Compliance and Carbon Markets' in Brunnée et al. 2012, supra note 2, 240-285. Ernestine Meijer and Jacob Werksman, 'Keeping it Clean: Safeguarding the Environmental Integrity of the Clean Development Mechanism', in David Freestone and Charlottee Streck (eds.), Legal Aspects of Implementing the Kyoto Protocol Mechanisms, (Oxford, UK: Oxford University Press 2004), 191-211.
} 
of the negotiations. ${ }^{116}$ The negotiations under Article 6 are now scheduled to conclude at CMA2.

Nevertheless, several key ETF MPGs related to Article 6 were agreed at CMA1. As a result, the Article 15 Committee, through its relationship to the ETF, will have a role related to Article 6 - regardless of whether the ongoing negotiations conclude successfully. Article 6.2 of the Agreement is to be implemented consistent with CMA guidance. This guidance was (partly) adopted at CMA1. Accordingly, under paragraph 77(d) of the ETF MPGs, each party that participates in cooperative approaches involving ITMOs 'shall provide' the information indicated in this section of the MPGs, as well as any additional MPGs later adopted under Article $6{ }^{117}$

It is possible to interpret two different ways in which Article 6 issues might reach the Committee. Under Mode 3, the information submitted by a participating party under paragraph 77(d), will form part of a structured summary of information reviewed by the TERTs. Because 77(d) is a 'shall' provision developed under Article 13.7 of the ETF MPGs, significant and persistent inconsistencies in a party's information provided, if they are identified in a TERT recommendation, could lead to a Mode 3 case.

It is also possible to interpret Article 6 issues reaching the Committee under Mode 2. Any party participating in cooperative approaches is under a treaty-based obligation to ensure that it is not double counting under Article 6, and to provide the information necessary to track progress towards its NDC under Article 13.7. Because the Agreement is silent on the channel through which Parties will provide information under Article 6.2, CMA1 decided that such information will be part of the 'structured summary' in the BTR. If a party is participating in cooperative approaches but fails to provide the information required under paragraph 77 (d), this might be considered a failure to provide information which it is legally obliged to. In this sense, the party can be considered to have not submitted a 'mandatory report or communication of information' under paragraph 22(a)(ii). As with other mandatory reports submitted under Article 13, the Committee, under paragraph 22(a)(ii) and paragraph 23, would assess only whether or not such information had been communicated, not its completeness or quality. It is not clear, however, how the Committee would know the party is participating in cooperative approaches without it having submitted such information. This might be revealed through the structured summary submitted by the other party to the transaction,

${ }^{116}$ See Draft text under item 7 of the agenda (third iteration, 8 December 2018), available at https://unfccc.int/process/bodies/subsidiary-bodies/ad-hoc-working-group-on-the-paris-agreementapa/information-on-apa-agenda-item-7.

${ }_{117}$ When CMA1 failed to reach consensus on matters related to Article 6, it noted that the information called for in para 77(d) 'is without prejudice to the outcomes' on these matters that will result from the ongoing negotiations on Article 6. This leaves the relationship between Article 77(d) and whatever may be eventually agreed at CMA2 on Article 6 somewhat unclear. See Decision 1/CP21, supra note 5, and UNFCCC, Matters related to Article 6 of the Paris Agreement and paragraphs 36-40 of decision 1/CP.21, FCCC/CP/2018/L.28 (2018), available at https://unfccc.int/es/node/187598. 
or through the databases and registries being discussed under the ongoing negotiations under Article 6.

It must also be kept in mind that the texts that will provide a starting point for the resumed negotiations under Article 6 propose a 'governance' arrangement which could include a distinct 'Article 6 technical expert review' that would start earlier and review the participating party's performance more frequently (annually) than the Article 13 TERTs. If these texts are eventually adopted, the Article 6 TERTs 'may make recommendations' to the party include 'how to address inconsistencies' with the reporting and accounting guidance. The Article 6 TERTs could forward their reports to the Article 13 TERTs and thereby, to the Article 15 Committee. ${ }^{118}$ They could also forward their reports directly to the Committee.

As regarding any other case under Modes 2 or 3, the Committee is to take appropriate measures in relation to these Article 6 cases, which could be tailored to Article 6 circumstances. In this context, it is important that such measures must be in keeping with the facilitative and non-punitive character of Article 15 and not impose sanctions or penalties.

\section{Summary and Conclusions}

The modalities and procedures are carefully designed to respect the transparent, nonadversarial, facilitative and non-punitive nature of the Committee's work. They also respect parties's sovereignty and parties' respective national capabilities and circumstances.

First, the prescriptive list of modes of initiation provide transparency and predictability. Any expansion of the Committee's scope would require a CMA decision or an amendment to the Paris Agreement. The Committee's annual report will be publicly available. ${ }^{119}$ The Committee may develop through its rules of procedure greater clarity on, for example, the role of its co-chairs, how to manage conflicts of interest, and the timing and reasoning of its decisions. The Committee has still to decide on how observers and the public might access information, observe or participate in its work.

Second, the modalities and procedures are non-adversarial in nature and in this sense distinct from the dispute settlement provisions provided for under Article 24 of the Agreement. Most significantly, they do not provide an opportunity for a party to initiate

118 The Katowice Texts, Proposal by the President, available at

https://unfccc.int/sites/default/files/resource/Katowice\%20text\%2C\%2014\%20Dec2018_1015AM.pdf, Draft CMA decision on guidance on cooperative approaches referred to in Article 6, paragraph 2 of the Paris Agreement, Annex, Sections II and VIII. See also SBSTA, Draft CMA decision on guidance on cooperative approaches referred to in Article 6, paragraph 2, of the Paris Agreement, Annex, para 35, available at https://unfccc.int/sites/default/files/resource/sbsta48.2 12a DT Outcome.pdf.

${ }^{119}$ PA, supra note 5, art. 15, para 3 and A15 MP, supra note 6, Annex, para 36. 
a case with regard to another party or in any other way to participate in another party's case. Under Mode 1 any party may seek help and advice form the Committee. The Committee can only apply facilitative measures, and cannot impose penalties, fines, fees, sanctions or enforcement measures of any kind. However, there will be an element of public and political accountability associated with the Committee's recommendations, including findings of fact, as these relate to the non-performance of the relevant provisions.

Third, the sovereignty of parties is respected primarily through their expression of consent (by ratification or other means) ${ }^{120}$ to be bound by the Agreement and to these modalities and procedures. Most significantly, the party concerned must provide its consent before the Committee can act on cases that arise from the implementation of and compliance with the ETF MPGs (Mode 3 initiation). And in general, the sovereign interests of all parties can be said to be protected through the elected and representative structure of the Committee.

Fourth, Article 15 and the modalities and procedures pay particular attention to a party's national capabilities and circumstances. ${ }^{121}$ Rather than including a reference to the principle of common but differentiated responsibilities and respective capabilities, in the light of different national circumstances, parties accepted that differentiation is addressed throughout the Agreement, ${ }^{122}$ and that the Committee would accord any additional flexibility, when needed, with regard to procedural timelines. ${ }^{123}$

In sum, we conclude that the modalities and procedures adopted at CMA1 have resolved enough of the Agreement's textual ambiguities and differences in parties' views to make the Article 15 Committee operational. At the same time, the modalities and procedures do not overly constrain the Committee, but leave it discretion to interpret them and to develop more specific, rules of procedure.

Thus the Article 15 Committee has the potential, similar to the various 'implementation' and 'compliance' committees under other MEAs, to enhance the effective implementation of the Agreement if it proves capable of generating incentives and disincentives that can both 'push and pull' improvements to parties' performance.

These incentives and disincentives could range from deepening parties' understanding of their obligations; clarifying the challenges faced and helping to design strategies to address them; assisting parties in accessing technical and financial support; raising the domestic and international political profile of and accountability for parties' performance with regard to the Agreement's and the Rulebook's most important

\footnotetext{
${ }^{120} \mathrm{PA}$, supra note 5, art. 20, para 1 and VCLT, supra note 10, art. 11.

121 PA, supra note 5, art. 15, para 1.

122 A15 MP, supra note 6, Annex, para 19 (c)

${ }^{123}$ Ibid., Annex, para 26.
} 
provisions; and making public cases of non-compliance or non-implementation in a way that creates an incentive to return to compliance.

The Committee will begin its work after its members are elected at CMA2. Its first cases could begin quite quickly under Mode 2, paragraph 22(a)(i), as the interim version of the public registry referred in Article 4.12 currently reveals that a number of parties have not yet registered a NDC. ${ }^{124}$ Parties with NDCs with a timeframe of 2025 will be expected to have communicated their new 'post-2025' NDC 9-12 months prior to CMA3. ${ }^{125}$

After all, it is important to recall that as with other aspects of the Rulebook, the modalities and procedures for the Article 15 Committee were adopted by CMA decision, and will be reviewed and can be revised on the basis of experience gained with their implementation. The first of these reviews will take place in $2024,{ }^{126}$ when that experience may still be limited as the cycles of reporting and implementation will only have just begun. The review may nonetheless provide an opportunity for improvements.

124 At the time of this writing (3 March 2019), there are 185 parties to the Agreement, and 182 with NDCs in the interim registry, available at https://www4.unfccc.int/sites/NDCStaging/Pages/All.aspx. ${ }_{125}$ Decision 1/CP.21, supra note 5, paras 23 and 25.

${ }^{126}$ A15 MP, supra note 6, para 2. 